\title{
The Analysis and Countermeasures of Female College English Teachers’ Burnout in China's Minority Areas
}

\author{
Ying Chen \\ Foreign Languages Department \\ Guangxi Normal University for Nationalities \\ Chongzuo, China
}

\begin{abstract}
Female English Teachers accounts for the majority of all English teachers in the colleges in Chinese minority areas. Compared with the male practitioners, the factors of occupation burnout that the professional women facing are more complex. This article focus on the situations of college English teachers' burnout in national areas in China from the female perspective, discuss the influences on the development of college English majors under the regional environment factors and current national policy, and analyze the causes and characteristics of job burnout for the female college English teacher in national areas in China, then put forward the coping strategies.
\end{abstract}

Keywords-minority areas; colleges; female english teacher; burnout

\section{INTRODUCTION}

China's western region is an ethnic minority region, the economic condition is relatively backward, the foreign trade cooperation and cultural exchanges are lagging. Since 2000, the Chinese government began to implement the strategy of west development, the plan included a series of constructions called "top ten projects", one of them are for the construction of western college educational infrastructure. The development of economy and culture need to introduce more advanced technology and ideas, so foreign language talents, especially English talent demand in these areas began to rise dramatically. So in college professional setting in national minority areas in China, English become one of the indispensable important majors.

According to the China job burnout index survey report that published by the China Human Resources Network, in the burnout index of 15 industries, college teachers ranked third, the burnout index is as high as 50.34. And the job burnout of female teachers are obvious among them [1]. According to the research of foreign teacher's job burnout, teacher is of high-risk groups. And teachers with higher education degree are more likely to suffer from job burnout than that with lower [2]. American teachers association point out in a 1983 study that $37.5 \%$ of the teachers have the Job burnout symptoms like the severe anxiety and mental tension.[3]

\section{RESEARCHES ON JOB BURNOUT}

\section{A. The foreign research on burnout}

The psychological concept of "burnout" was first proposed by Freudenberg in 1974, Which is defined as the weary situation that caused by the large workload, the long work time, the high work intensity and ignore the individual demand.[4] The research conclusion that made by Maslach's group in the 1980s is widely accepted and cited currently. In his work, he study burnout from the perspective of three main analysis, namely the emotional exhaustion, depersonalization and reduced personal accomplishment. The psychologist Faeber argues that the behavior of job burnout is different on individual performance. It mainly performs as three forms: burnout, frenetic and underchallenged. And the three forms are often mixed cross. [5]

\section{B. The domestic research on college English teachers' burnout}

Many domestic research results of burnout are based on the theory of the western scholars' study, and are mostly about primary and secondary school teachers' burnout research. According to the records that search from China national knowledge internet, the earlier study on burnout from the perspective of college was published by Li Zhaoliang who is from school of public health, Jilin University in 2006. And this paper was published as a medical research on a National Medical Journal. For the recent 5 years, some scholars start to research college teachers' burnout problem from regional point of view. So we can found some papers on the topic that written by scholars from Chinese ethnic minority areas like the Inner Mongolia, xinjiang and Tibet and so on. With the development of the western China development plan, the Chinese ethnic minority areas have a great development on both economy, culture and education. With the Social and economic conditions change, the causes of teachers burnout factors also need a further update and complement. 
III. The Analysis Of The Cause Of Female English TEACHER Burnout In CHINA's ETHNiC MinORITy AREAS

A. The social environment factors - The environmental characteristics of the colleges in China's ethnic minority areas and its impacts

1) The characteristics and influences of geographical locations.China's ethnic minority areas refers to the together living area of ethnic minorities, which is mainly distributed in the border area of the north and west of china, for example the provinces like Guangxi, Inner Mongolia, Xinjiang, Tibet and Ningxia. These areas are of a wide land with primitive ecological environment and complex terrain structure. The Relatively closed geographical environment makes these areas with less outside exchange opportunity. English, the universal language to communicate with the world, is not that popular there at first. Due to the fact that English takes few opportunities for practical use in daily life in that areas, the development of the college English major is hard to compete with the developed areas no matter on the teaching environment or the teaching level. To achieve the teaching effect, need the college teachers there are required to invest more energy and patience.

2) The characteristics and influences of the economic environment. Compared with the developed areas in eastern China, China's ethnic minority areas have a relatively backward economic development in a long time, the infrastructure construction and traffic condition is inferior to the eastern big cities. In addition, the wages there is at a low level compared with the national level. Even though the economic situation has improved today, it is still with a great gap between developed regions. The unequal between input and return will inevitably lead to anxiety and discontent, which make it a difficulty to attract senior English education talents to come here. But, Because of China's western development program, the state began to increase the investment in higher education in ethnic areas. A lot of money is used to improve the education equipment and facilities there. As the improvement of local traffic condition, and English talents has reached a saturation point in the developed region, more advanced English teaching talents start to seek opportunities in western minority areas.

3) characteristics and influence of social, historical and cultural environment. For a long time, China's ethnic minority areas mean poverty, backwardness and wild. After years of national development and construction, these regions have gradually formed some small and medium-sized cities. As the import and export of resources, China's ethnic minority areas started to get frequent cultural exchanges with the outside world, the demand for English talents in these regions began to increase. But almost every ethnic minority areas in China have their unique national languages, which making the local language environment constitute a relatively complex one, and many problems are encountered in the process of English majors teaching. For example, the multiple language pronunciation habits and rules will affect the English learning and teaching effect. In addition, the college English learning is already entered the stage of professional language learning, and local talent cannot meet the teaching talented demands in these ethnic areas on both the quantity and knowledge level. The introduction of foreign talent becomes necessary.

4) Composition characteristics of university students' enrollment in ethnic minority areas. To ensure that citizens of various levels and various nationalities can receive equal opportunities and rights of all types of education, in 1980, the ministry of education and the state ethnic affairs issued the opinions on strengthening national education work which is approved by the state council. Including provisions: "In the college entrance examination enrollment, the Admission should combine competition with proper favorable policies for minority students. In the national autonomous areas, the proportion of minority students admission should strive to not less than the proportion of ethnic minority population". Then in 2006, the student amount of the 6 colleges which are under the charge of the state ethnic affairs had reached 91000, including 55 ethnic minorities. In the central university for nationalities, the minority students were above $70 \%$, the other five colleges of minority students' proportion is above $60 \%$.

Limited by the geographical location, traffic environment and the influence of living environment, minority students' proportion is higher in the colleges in minority areas. Considered the urban and rural education level difference and the drop points admissions regulations, minority students' education level is lower than that of developed regions. And the college English teachers that introduced from other places will meet some conflict between the teaching method and receptivity. Both teachers and students need time to adjust to each other.

B. National policy factors - The current examination policy and employment policy put forward new requirements to the reform of college English education in ethnic areas

1) The requirements of students English level under the China's overall economic environment. The current development of China's overall economic situation is very good, as the main communication language, English play an important role in the frequent communication with Englishspeaking countries. However, the current demand for economic and trade tends to employ those language talents with more advanced and solid language foundation and comprehensive ability. The current job market is still under the influence of traditional concepts, many companies still put great concern on the certificates that represent the skills students master. At the same time, in order to deal with the future possible development opportunities, form the talent pool for the company, many companies pay great attention to those non-English major students' English ability even when they providing job not related to English. 
2) Problems existing in the English Course Setting in the college of ethnic minority areas. The current Chinese college English subject is divided into professional and nonprofessional. The course setting for Professional English seems traditional and old today. The courses that the subject design for students still focus on listening, speaking, reading writing and translating, the 5 basic language skills. In minority area, most of the education reform ideas is following the developed areas, the knowledge structure of teaching reform concept have a slow update, and the teaching ideas that imitate from developed areas blindly might not suitable for the situation in minority areas. As the students' English quality level there has a big gap with the developed area, they get a limited employment prospects. And that put forward a higher requirements for English teachers to update their knowledge structure. Even though the language ability requirement is relatively lower than professional level, those non- English major students still facing the pressures of passing certain English level test, which put the same stress for teachers on the passing rate.

3) The pressure caused by the English teaching reform and new national college entrance examination policy. In recent years, China's education has focus on English course excessively, which causes a series of problems in cultivating students' Comprehensive ability. Because English is one of the subject of college entrance examination, in order to improve the primary and middle school students English, many sports and art course are clear out from the curriculum or put very little attention. To cope with the English level test, college student often put too much energy on learning English, but ignored the professional courses study. As a result, primary and middle school students' schoolwork burden is overweight, and college students' professional learning goals become ambiguous. So today, the call for English course reform is also rising.

In 2013, national ministry of education website published part of the detailed rules for the college entrance examination English reform. English college entrance examination will consider to have the English test several times a year, and choose the highest score as the final grades for college entrance. Since there is a change on college entrance examination, the emphasis of the teaching content and teaching methods in the college should also make an adjustment. Before more details of the reform come out, there will be a lot of anxiety and confusion for most English teachers

4) The pressure of college English teaching in ethnic areas from national employment policy.The plan of west development helps many ethnic minority areas to build a lot of colleges and universities. But these colleges and universities did not fully consider the market demand before designing the subjects they offer. As foreign trade and frequent cultural exchanges, and more people hope to understand the outside world, English major has become a popular major for almost all the colleges. However, in recent years, according to the data of employment, many traditional majors meet difficulties in employment market, even in those developed areas. And many Chinese students' employment concept is traditional, for example in Jiangsu province, education department statistics show that in 2014, 69.8\% of the total number of graduates choose to work in Jiangsu, only a third of the graduates willing to get job in another province. Even if there is great pressure, many students refuse the job opportunity to work abroad.

In order to promote the college students' employment rate, to encourage the entrepreneurial enthusiasm of college graduates. College graduates that founded a small meagreprofit enterprise can enjoy the relevant tax policy, loans discount and other supports. However, most English major students focus on a single language skill learning, and lack the trade knowledge and computer skills that match the needs of labor market. Therefore, even those students who has better master the language skill is facing a big pressure, let alone those from ethnic areas colleges students whose language level and knowledge structure is relatively weaker. The severe employment situation causes the college English teachers in ethnic minority areas a great sense of crisis.

\section{Career prospects factors -- The factors that limit the female college English teachers' career advancement prospects in minority areas}

1) The composition of college English teachers in minority areas.Influenced by traditional ideas as well as women's delicate and patience character, in China, teacher is often considered as one of the most suitable career for women. And research has shown that women's language ability and performance ability are better than men. According to the sex ratio of university English majors in China, there are more women than men significantly. And that is also the reason why there are more female college English teachers than male. According to the research of the Li zhao-liang in 2006, female college teachers' emotional exhaustion is significantly higher than that of male teachers. [6]

2) The influence of regional environmental adaptation. The composition of College teachers is different from that of primary and secondary school in the minority areas. Many of them are not the local people, but the foreign talent that college introduced from developed areas and top universities in order to reasonable the college's talent structure. As the special Local habits, customs and complex language environment, those foreign talent need a long time to adapt themselves to the living environment, especially for those female teachers who have the strong sense of family. They left their home land and feel lonely in a place with communication problems, they are far from family and difficult to take care of their parents and job at the same time. Then their anxiety problems will affect their teaching atmosphere and the teaching effect. Perhaps they can control this kind of emotion in a short period of time, but the depression will hurt these women teachers' mental health in a long time. 
3) The influence of traditional family values. When these female English teachers who are working in colleges in minority nationality areas arrive at their ideal age of marriage, they will face the difficult choices. While minority areas are affected by Chinese traditional idea even more serious, men are often the center of the family, and women had to invest more energy in the family than men after marriage. When these female college English teachers want to keep balance between family and career development, their will have greater inner conflict and pressure than male teachers. Especially for the married women who have children and elderly parents in family.

Thang Shujun's research shows that social support plays a link and intermediary role in dealing with the college teachers' conflicts between family and job and their burnout. [7] According to a survey on college teachers' living conditions made by Yan xiaoping, $60 \%$ of the housework is mainly borne by the female teachers in the family, only $7.6 \%$ family that husband taking housework mainly[8] traditional social concept also believes that men have more advantages than women in their careers, so most female colleges teacher choose to sacrifice themselves, even when they meet family conflict, it is difficult to get the understanding and support of the society. [9]

4) The influence of career advancement tradition.For position promotion, there is a traditional unwritten rule. Because of the physiological differences, Men have more advantages than women. Even in the file of English teaching that female take the majority, academic work is still considered a male advantage areas, women take a relatively weak position in this field. The main problem that college female English teacher are facing is that the proportion of senior titles still at a low level. The institution system of teaching evaluation that focuses on scientific research but ignore teaching work is the obstacle to women's promotion. [10]

5) Double pressure of teaching task and research mission. Compared with the developed areas, the attraction to highlevel talent for colleges in minority area is less, while the teaching task is heavier. On the one hand, minority areas' colleges wants to introduce more male English teachers who do not have the childbearing period to release the workload, but on the other hand, with the limit of particularity of English major, this goal is hard to achieve. Technical titles promotion is an important target of all college teachers, if female English teacher want to promote their title, they have to overcome their childbearing period, guarantee the quality of teaching and set aside time for research work at the same time. So the research pressure they faced is more than male teachers.

\section{The Influence Of Female Colleges English} TEACHERS' BURNOUT IN CHINA'S ETHNIC MINORITY AREAS

For female college English teachers in China's ethnic minority area, they must both guarantee the teaching quality, complete the teaching mission, to take care of the family, and the scientific research work. It's really hard for them to satisfy all of these aspects. They will easily fall into a state of emotional exhaustion under such multiple pressures. There is an interaction between teachers and students in the overall learning atmosphere. Teachers' negative emotions can easily affect students emotion that lead to a low teaching quality, slow research progress, and reduced personal accomplishment eventually.

\section{COUNTERMEASURES AND SUGGESTIONS}

\section{A. Integration into the local culture and society actively}

Since you had decided the college English teaching as your career direction in minority areas, you should integrate into the local culture and society when facing the unfamiliar environment. Try to learn some local language and make friends with the locals. If the local custom activities do not make you hard to accept, try to participate in some of the activities.

\section{B. Making a long-term plan of your career}

As a college English teachers that work in the minority areas, you should improve yourself professional recognition, don't just consider the current interests. The investment in minority areas is increasing with the national economic growth. There is also a huge talent gap to be fulfilled in a long term, compared with the developed areas, you can get more job opportunities as well as promotion opportunity, and receive attention and recognition more easily.

\section{Continuous learning}

Learning continuously to improve your knowledge structure, summarizes the experience from your teaching. Learn to cooperate with team work, no one can live on their own ability to solve all problems. Let yourself keep the young mentality and active positive thinking by keeping pace with modern life. Only the teacher with physical and mental health, can have an active mind in finding more effective teaching methods.

\section{CONCLUSION}

It is difficult to change the phenomenon of high proportion of female English teachers in colleges in China's minority areas in a long period of time. For the long-term development of the English majors, it is very necessary to deal with the burnout problem of these female college teacher. The individual sense of identity and achievement Promote a person's career advancement. The burnout feeling will influence more than individual professional attitude and behavior. If the negative feeling spread and become common, it will affect the operation of the whole team, and hinder the progress and development of the whole industry. Professional development needs the teachers' personal constantly learning and reflection, while the motivation lies in the identification of the professional.

\section{ACKNOWLEDGMENT}

The study is supported by Education Department of the Guangxi Zhuang Autonomous Region in China: The Study of Female College English Teachers’ Burnout in China's Frontier minority areas (KY2015LX549) 


\section{REFERENCES}

[1] Long Qiu-yuan. Female University Teachers' Burnout Analysis and Countermeasures [J]. Teacher's resources, 2012, (6) :127-128.

[2] Su Su-mei. A discussion on American teachers "job burnout"[J]. Journal of education information abstract, 1995, (3) : 21-22.

[3] Yang Xiu-yu. A Commentary on Teacher Burnout Study in the west [J]. Studies in Foreign Education, 2005, (11) : 67-71.

[4] Frendenberger H j. Staff Burnout [J]. Joumal of Social Issues, 1974 (30) : 159-165.

[5] Chen Qi. Contemporary education psychology [M].Beijing: Beijing normal university press,

[6] Li Zhao-liang. An Investigation and Counter measures on Burnout of University Teachers [J]. Medicine and Society, 2006, (11) : 49-52.

[7] Thang Shu-jung. Study on College Teachers' work-family Conflict and job Burnout: the Mediation Role of Social Support [J]. Education Research Monthly, 2010, (9) : 35-53.

[8] Yuan Xiao-ping. The research of Female College Teachers' survival situation from the Perspective of Humanism [J]. Education Review, 2012, (4) : 48-50.

[9] Yang xiao-chun, Guo Xiao-ying, Huo ya-feng. An Investigation on Types of Female University Teachers' work Family Conflicts and
Factors Causing the Conflicts [J]. Journal of Hebei United University (Social Science Edition), 2012, (2) : 5-7.

[10] zhao Ye-zhu. An Analysis on the Status of Women Faculty on Higher Education in China [J]. College Study \& Evaluation, 2012, (2) : 5-7 